\title{
LA IRONÍA COMO SABOTAJE DEL DISCURSO METAFÍSICO EN “BON-BON” DE EDGAR ALLAN POE
}

\author{
IRONY AS A SABOTAJE OF METAPHYSICAL \\ DISCOURSE IN “BON-BON” BY EDGAR ALLAN POE
}

Leyla TORRES BRAVO

Universidad de Talca (Chile)

Resumen: Este artículo propone un análisis de la lectura y la figura representativa del lector y su reducción alegórica, basándonos en los postulados de la Teoría de la crítica como sabotaje o modelos de mundo de Manuel Asensi. De esta forma, se atienden y exploran las particularidades más relevantes que, en el relato corto de "Bon-Bon", de Edgar Allan Poe, sustentan la estrategia silogística que, desde la ironía, utiliza el escritor estadounidense para formular su profunda denuncia contra la metafísica.

Palabras clave: Lector; crítica como sabotaje; silogismo; ironía; metafísica.

Abstract: This paper aims to analyze the representation of the figure of reader and his allegorical reduction based on the criticism as a sabotage of Theory of World's Model by Manuel Asensi.

Thus, I explore the more relevant aspects that finds in the short story of "Bon-Bon" by Edgar Allan Poe. Likewise, I review the support the syllogism strategy that, from the irony, the American writer uses in order to formulate his profound complait against Metaphysics.

Keywords: Reader; criticism as a sabotage; syllogism; irony; metaphysics. 


\section{Introducción}

La obra narrativa de Edgar Allan Poe pone énfasis en conseguir, por medio de un arduo trabajo creativo y estilístico, el interés del lector. Esta premisa resalta los modos en que su escritura contradice a la crítica literaria, lo cual, a su vez, implica una férrea ruptura con sus márgenes reduccionistas. Pero, a pesar de la discrepancia que el escritor mantiene con esta, y que, de hecho, le deja fuera de las clasificaciones literarias convencionales, también es posible hablar de una nueva lectura respecto a su aporte narrativo, como lo hace Brett Zimmerman (2005). Con estos antecedentes, el autor especifica que los trabajos literarios de Poe ahora pueden ser leídos, en su conjunto y bajo la óptica de sus trasgresiones, especialmente, en lo tocante a los lineamientos generales de las conocidas tipologías tradicionales.

Desde esta perspectiva, Zimmerman dice que tanto las figuras retóricas como las alusivas a sus aspectos gramaticales demuestran que el escritor estadounidense construye un relato nuevo que no sigue una lógica narrativa fija. Todo ello, gracias a la función mediadora de la técnica literaria. Por eso y, en concordancia con la revisión que haremos más adelante, este aspecto despierta nuestro interés acerca del estilo concienzudo y deliberado de Poe. En su opinión, la narrativa de Poe, a través de la superposición estilística, además coincide con algunas clasificaciones y patrones que, desde una mirada contemporánea, hacen una directa o indirecta relación con ciertos trastornos psicopatológicos que rigen su personalidad. Desde allí, se hace posible ver cómo él aplica la técnica literaria y, en consecuencia, la entrelaza con su creatividad. A la luz de esto, el autor explica que los seguidores literarios actuales de Poe están lejos de conocer las condicionantes antes señaladas de su escritura.

Respecto a la narrativa de Poe, nosotros vamos a explorar en este trabajo cómo opera y aparece en escena, en su obra "Bon-Bon", la figura del lector junto con su recepción lectora. Por esta razón, recurrimos a los postulados de la Teoría de la crítica como sabotaje o modelos de mundo de Manuel Asensi, con el objeto de rastrear los patrones de análisis que engloban su representación mental, además de su recepción frente al discurso metafísico. De ahí que se analicen las formas que asume el silogismo y que, en un sentido concreto, acaban emitiéndose a través del modelo de mundo psíquico y textual que se vislumbran en el relato.

\section{La narrativa de Poe y su relación con lector en el relato corto de "Bon-Bon"}

"Bon-Bon" es un relato corto escrito por Allan Poe en 1831 y publicado, primeramente, bajo el título The Bergain Lost, en el periódico Philadelphia Saturday Courier. Más tarde, sin embargo, será divulgado como "Bon-Bon" en el Southern Literary Messenger, en 1835 (Sova, 2007). Como se observa, el escaso margen temporal que se presenta entre ambas versiones, refuerza ciertos aspectos 


\section{Leyla Torres Bravo}

descriptivos y estilísticos que emergen como resultado del encuadre más riguroso y, a su vez, metódico de la obra definitiva.

El relato en su versión original y final narra la historia de un aficionado lector metafísico, quien es, además, un sujeto altamente refinado y pedante. En un principio, Poe utilizó al veneciano Pedro García como personaje principal de su historia. Luego, en su versión definitiva, consideró más pertinente colocar como protagonista al también metafísico Pierre Bon-Bon. Ambos personajes comparten su pasión por la metafísica y su arrogancia como forma de vida, aunque, ciertamente, difieren en otros aspectos, tales como su residencia y otros pequeños detalles. De acuerdo a esto último, en The Bergain Lost, se aprecia que Pedro García es un residente veneciano, quien, de hecho, se jacta de su noble ascendencia.

Nosotros, en este análisis, consideramos solamente la versión definitiva del autor, es decir, "Bon-Bon". Más adelante fijaremos de nuevo la mirada en su protagonista. Ahora lo que nos interesa, en este apartado, es lograr un acercamiento a esta obra y a la escritura de Poe, revelando tanto su técnica literaria como su intencionalidad comunicativa.

En primer lugar, en lo que respecta al narrador, queda en evidencia en "Bon-Bon" una reconfiguración sólida de su voz testimonial. Es lógico, así, que se le emplee como un recurso recurrente, por medio del cual se acaba dando forma y dinamismo a la historia de acuerdo con sus descripciones y reflexiones irónicas. Es en este plano narrativo donde Poe revela una doble dimensión de su propia personalidad, que actúa propiciando la entrada en el texto de su amplia erudición filosófica y filológica, la que, además, claro está, conjuga con toda su experiencia y creatividad literaria.

En concordancia con la configuración narrativa de Poe, resulta de interés para este trabajo considerar, en términos generales, la premisa que el escritor sigue mediante el rescate de la técnica de composición literaria. Asunto que, como sabemos, tiene como trasfondo dar cuenta del uso intencional de tropos o modos discursivos, que marcan la denuncia burlesca de esta obra. De ahí que esto se materialice en sus polifacéticas obras, entre las que se incluyen cuentos, poemas y novelas. Y, en las que, principalmente, como es sabido, además se entretejen amplios géneros narrativos de índole policial, gótico o de ciencia ficción. Pero, sin duda, será en sus ásperos ensayos y críticas literarias, donde el escritor consiga un espacio abierto para reafirmar y poner en evidencia toda su defensa de la composición literaria.

A propósito de esto, es acertado decir que para el escritor el respaldo de su creación literaria, es algo que se asienta dentro de su tarea por conseguir la perfección comunicativa de sus obras. Visto de este modo, también se aprecia desde allí, que Poe desea e intenta conseguir un auténtico y, a la vez, impactante acercamiento de carácter literario con sus posibles lectores. Como resultado final, se observa que su interés y empleo por la técnica literaria, coincide con una posición teórica que, a grandes rasgos, deja huellas en su ardua y potente rivalidad con la teoría de la inspiración (Asensi, 1998). Todo este asunto, de hecho, se visualiza con plenitud cuando se estudia y analiza la historia de la teoría literaria. Curiosamente, se advierte allí que la propuesta de Poe, de algún modo, se anticipa 


\section{Tropelías. Revista de Teoría de la Literatura y Literatura Comparada, 33 (2020)}

a los postulados del formalismo ruso. Incluso, se ha llegado a especificar que sus ideas son ampliamente compartidas con la rigurosidad técnica que se detallada en la poética formalista, es decir, la literariedad (Gil Guerrero, 2008; Matamoros, 2011).

De esta manera, será en su ya célebre ensayo La filosofía de la composición donde el escritor defienda, desde luego, la cuestión de la rigurosidad técnica, con el objeto de orientar la forma con la que se construye el argumento del relato, así como el detalle descriptivo de su escenificación (Asensi, 1998). Y es aquí, donde se parte de la certeza de que esta, como aspecto definitorio de su escritura, tiene un profundo alcance para la subjetividad del lector. En efecto, por medio de la atención que Poe otorga a la técnica literaria, se activan los diversos modos con los que se erige la cohesión de la trama y su impacto sobre el lector. Creando así un marco, desde el cual se bosqueja la historia misma que da vida al relato, instalándose como base narrativa el desarrollo de su novedad y brevedad dispuesta en su contenido (Pizarro Obaid, 2011).

Es claro tal y como acabamos de revisar, que su respuesta se edifique y difunda teniendo como primordial punto de referencia la rigurosidad que acompaña el uso de la técnica de composición literaria. De ahí que, a pesar del paso del tiempo, pensamos que una lectura más atenta de su marca autoral puede llevarnos, quizás, a un posible reconocimiento universal, el que cubriría sus amplias y significativas obras, a pesar, claro está, de las críticas de sus oponentes literarios.

Por esta razón, la relación con la técnica literaria y su correlación respecto a la intencionalidad del escritor, se hace patente en su anhelo por captar tanto el placer como la complicidad del lector. En torno a esto, por ejemplo, es de interés para algunos estudios psicológicos revisar cómo se produce la cuestión de la intersección cognitiva y emocional que surge entre el sujeto y el texto literario $^{1}$.

En suma, de ahí que sea importante encontrar los aspectos técnicos y discursivos desde los cuales se concibe el sabotaje del relato. Y, exactamente, aquí vemos que todo el proceso creativo del escritor está asentado en la rigurosidad técnica, como señalábamos anteriormente. Es así como, en términos generales, por este anhelo de superar su creatividad, al igual que el alcance comunicativo de su narrativa, el escritor enfatice y dinamice su propuesta mediante, como se ha dicho, la oportunidad de encontrar la configuración silogística en el relato corto de "Bon-Bon".

\section{La crítica como sabotaje y el acto lector}

La crítica como sabotaje o modelos de mundo se inscribe, en términos generales, como una propuesta teórica que gira en torno a la deconstrucción aplicada del discurso. Lo curioso y nuevo es

\footnotetext{
${ }^{1}$ Así pues, por ejemplo, en la toma de experiencia lectora de Kaufman y Libby (2012), se exhibe un intento por verificar el modo en que se produce la trasposición de la identidad del lector con la personalidad, los sentimientos y el accionar de algún personaje literario. Igualmente, Kidd y Castano $(2013,2017)$, se preocupan por revisar, sobre todo, los efectos sociocognitivos de la lectura de ficción literaria mediante los postulados de la Teoría de la mente. Por su parte, Turner y Felisberti (2018), estudian la forma en que la ficción permite a los lectores simular las experiencias sociales experimentadas por los personajes, concluyendo que, en efecto, facilitan su prosocialidad al promover positivamente su empatía y altruismo.
} 
que también pretende desintegrar esa misma deconstrucción (Asensi, 2013) ${ }^{2}$. A partir de ello, Asensi amplía su teoría más allá de la esfera y alcance de la propuesta deconstructiva de Jacques Derrida y Paul de Man. Para su fundamentación, el autor recurre a la distinción de premisas discordantes y compatibles con la célebre propuesta deconstructiva del texto literario y de la hermenéutica ontológica (Asensi, 2011b, 2013). Desde esta posición, se constata que su teoría, además, se respalda siguiendo el aporte inquisitivo de una vasta gama de enfoques teóricos, entre los que destacan, la teoría crítica de Van Dijk y el feminismo-teoría queer.

Evidentemente, la alineación de la teoría con el análisis del discurso denota que se trata de una vía privilegiada para disponer y lograr que el lector o espectador consiga una postura crítica frente a los discursos políticos hegemónicos (Caballero, 2013). A este respecto, se aprecia que, además, resulta válido ampliar su aplicación a las diversas modalidades semióticas que, de hecho, son parte de la ciencia, la filosofía, la historia, la literatura y los estudios culturales -por mencionar solo algunos de sus alcances- y que, igualmente, se constituyen como objeto de análisis para realizar un posible sabotaje de sus silogismos (Asensi, 2011a, 2013). Es, en este punto, donde aparece otra idea del autor que tiene relación con el hecho de que todo discurso inserto en algún texto asume una acción performativa y modeladora sobre el lector. El asunto se plantea con bastante exactitud en las siguientes palabras de Asensi:

Todo discurso presenta un modelo de mundo análogo al modelo de mundo-entorno del receptor, y que dicho modelo discursivo posee, en virtud de esta misma analogía, una capacidad apelativa, incitativa y performativa capaz de modificar o rectificar la subjetividad del sujeto (2018, p. 312).

De este modo, se le hace posible sostener la noción de que en toda narrativa se establece una comparación o contraste con la realidad. Así, es el lector quien construye un modelo de mundo que se ajusta y traduce con la manera de comprender, de sentir y de poner en evidencia las premisas del texto. Aquí radica, entonces, la atención de Asensi respecto al impacto que ejerce, desde la realidad cotidiana del lector, el contenido de los mensajes expuestos en la literatura.

Es interesante observar que, en un sentido similar, el planteamiento general de la Teoría de los modelos mentales de Johnson-Laird (1983, 2006, 2010, 2012) propone que el sujeto construye, a nivel cognitivo, inferencias semáticas de acuerdo con la información que obtiene de los mensajes comunicativos. En tal sentido, la teoría concluye, a nivel teórico y experimental, que las personas crean en su mente un modelo icónico o representativo de la realidad, el cual muestra ciertas posibilidades de ocurrencia para la circunstancia previamente descrita. Por lo tanto, para la teoría, la semántica resulta ser un asunto importante dentro de la cognición humana, dado que permite la construcción de modelos mentales, aunque acepta también la función que asume la pragmática junto con las variables contextuales que influyen en ella. Negando con ello toda participación a la lógica mental (López-Astorga, 2019). De acuerdo a lo expuesto, es posible decir que ambas teorías se

\footnotetext{
${ }^{2}$ Más que deconstructiva la Teoría de la crítica como sabotaje, según Calaffel Sala (2012), se presenta como un procedimiento analítico de carácter metacrítico.
} 


\section{Tropelías. Revista de Teoría de la Literatura y Literatura Comparada, 33 (2020)}

interesan, desde distintas miradas, por la relación que surge entre el sujeto y la realidad. Esto, a su vez, ponen en evidencia la existencia de un desajuste que se produce entre la información literal y la interpretación que, a partir de ella, efectúa el sujeto. A pesar de sus diferencias, para las dos teorías se antepone el hecho de que todas las expresiones del lenguaje están, de algún modo, presentes en la información que recibe el lector.

En tal sentido, según la teoría de Asensi, las personas no solamente disponen del detalle de las descripciones o emociones ficticias del mundo literario, sino que, además, reciben información desde su conocimiento adicional, el cual se forja gracias a su constante interacción con la realidad circundante. Lo que se aprecia, entonces, con respecto a lo expresado, es el poder y predominio que detenta el silogismo, característica que lo hace poseedor del sabotaje discursivo y del avance de los modelos de mundo presentes en una obra. En resumen, lo antes expuesto tiene abiertas repercusiones en la decisión de Asensi de circunscribir los límites de acción de su teoría. Es así como el autor reconoce que el eje de su teoría es el análisis del discurso y, por esta razón lo sitúa por encima del plano meramente estético.

Queda decir, igualmente, que la función del lector y su posición frente al texto se constituye en otra de las dimensiones en la que se provee una auténtica proyección y encuentro de la teoría con el ámbito literario. En concreto, este asunto se plasma con amplitud, sobre todo en cuanto al despliegue de la subjetividad, porque el texto literario, por así decirlo, ofrece al sujeto diversas claves para canalizar sus posibilidades sobre el pensar, auto-representarse y actuar en un doble sentido, es decir, dentro o fuera del mundo interior del relato (Asensi, 2016).

Otro aspecto que habría que mencionar y que está relacionado con lo antes expuesto, tiene que ver con el asunto de la función y la tipología que la teoría asigna a la aplicación e interpretación del concepto de modelos de mundo (Asensi, 2016, 2018). Por esa razón, lo trascedente aquí no es, en rigor, el concepto como tal, sino lo que este hace en la subjetividad del lector. Asimismo y, en concordancia, con los últimos y generales avances de la teoría, resulta oportuno decir que, precisamente, la búsqueda más acabada de nuevos elementos se constituye en un rasgo que, en suma, determina y afianza la categorización de los tipos de modelos de mundo que tienen lugar en el medio textual. A propósito de ello, revisamos aquí brevemente las tres categorías de modelos de mundo, en tanto que se trata de elementos fundamentales para la teoría. Como resultado de esto, aparecen mencionados tres aspectos que sostienen a cada una de las categorías, tales como son el medio textual, el lector y el entorno. Es evidente que el primer modelo de mundo esté relacionado directamente con el discurso que se presenta en el texto. De hecho, su funcionamiento está acorde con la perspectiva estética y, en mayor medida, con la intencionalidad discursiva que le infunda su autor. El segundo modelo remite y se manifiesta en torno a la actividad cognitiva del lector o espectador. Y, el último, enuncia el modelo referencial, haciendo con ello mención al entorno desde el cual se ven estructurados los otros dos modelos. A partir de los modelos de mundo, observamos cómo aparecen en escena dos elementos que inciden y dan cuenta de la relación entre el discurso y el 


\section{Leyla Torres Bravo}

lector, a saber: por un lado, la reducción alegórica y, en segundo lugar, la modelización performativa del sujeto.

Destáquese que la reducción alegórica, vista a la luz de la crítica como sabotaje, en palabras de Asensi, es definida como "el mecanismo en virtud del cual el lector o espectador refiere lo universal del modelo de mundo del texto a lo particular de su propio mundo" (2018, p. 315). De hecho, es la Literatura, en sus diversas perspectivas, la instancia en donde se insertan un sinfín de posibilidades que dan cabida a la aparición de modelos de mundos posibles. De esta forma, se aprecia que están de por sí conectados en algún punto con la realidad. Lo que claramente se observa, según Asensi, en la asociación que surge entre el discurso del texto y la reducción alegórica que efectúa el lector, el cual, traslada desde el relato sus pensamientos y expectativas a su propia realidad. Un proceso similar ocurre con la modelización del lector.

En tal sentido, Asensi (2018) plantea que un texto es capaz de modificar el marco de creencias, conductas y comportamientos del sujeto. Pero hay que considerar también que, los motivos y deseos de la acción comunicativa del texto, están en directa relación con la opinión del sujeto. Por esta razón, dependiento del discurso que se formula en un texto o film, el sujeto tiene la opción de dar su conformidad o estar en desacuerdo con sus premisas. Para tal efecto, el sujeto debe verificar la coincidencia del discurso con respecto a su modelo de mundo, el que, precisamente, está prefijado en su mente. A lo que se agrega, por cierto, el placer subjetivo que este consigue cuando obtiene la confirmación del discurso.

En relación a lo antes indicado, Asensi $(2007,2011$ b, 2013, 2018) precisa que los discursos que son emitidos en el texto se originan y pueden ser entendidos, en términos generales, desde el polisistema que los envuelve. De acuerdo con esta premisa, el autor sostiene la existencia de elementos comunes y diferenciadores del discurso, que son los que, en definitiva, conectan directa o indirectamente sus aspectos textuales con el entorno del sujeto. Tal asunto, deriva, precisamente, del hecho de sostener que es en el silogismo donde se traza el significado y el sentido de la realidad.

A este respecto, desde la reducción alegórica, Asensi enmarca su plan de acción teniendo en consideración la estructura silogística del texto. Lo que, en definitiva, pone en evidencia la necesidad de construir, en el sujeto, un modelo de mundo que se deriva de las premisas y de sus conclusiones. Desde estas últimas, se hace posible llegar a contemplar el silogismo del relato, para clarificar su objeto y el modo con el que éste ejerce su efecto apelativo y performativo sobre el lector.

Resulta, por otro lado, especialmente significativo para nuestros fines considerar lo expuesto en la Teoría de Asensi con respecto a su propuesta de aplicación analítica de textos, desde su propia tipología de lectores. En concreto, la teoría se respalda en dos tipos: un lector obediente y otro desobediente. Como se puede apreciar, el primero, en rigor, incluye a un sujeto que logra, sin mayores problemas, asimilar el mensaje expuesto u omitido en el texto. En cambio, el lector desobediente, encierra a un sujeto que está muy atento al discurso y, por esta razón, es capaz de detectar y analizar su silogismo (Asensi, 2013). 


\section{Tropelías. Revista de Teoría de la Literatura y Literatura Comparada, 33 (2020)}

En resumen, podemos señalar que el lector ficcional en el relato corto de "Bon-Bon" es un personaje que actúa como cómplice de la denuncia irónica puesta de manifiesto por el escritor estadounidense. Acción que se conjuga, igualmente, con la aparición de la reducción alegórica y de los modelos de mundo que, en su conjunto, apuntan a hacer partícipe al individuo al captar y significar la realidad. De este modo, lo que se prioriza aquí es el vínculo establecido entre lector, texto y entorno. El que se constituye en una perspectiva muy especial, pues el escritor toma una posición ideológica y epistemológica que, en rigor, se revela mediante sus estrategias literarias de carácter retórico. Y así también, cuando demuestra sus amplios conocimientos metafísicos, junto a su bagaje cultural y a su pasión por la técnica literaria. No obstante, se puede decir además que es el lector quien debe, en definitiva, reconstruir tanto los modelos de mundo de la historia como el modelo de mundo que vislumbra en su propias reflexiones acerca de lo narrado.

\section{El relato corto de "Bon-Bon" como sabotaje irónico de la metafísica}

En primera instancia, resulta indispensable decir que el relato corto de "Bon-Bon" cumple con la condición de texto atético ${ }^{3}$. De esta forma, la historia se inscribe en esta categoría, porque su narración evidencia, en lo que respecta a Poe, su abierta y crítica oposición ante el estatus epistemológico de la metafísica. A título ilustrativo, el escritor reafirmará, en esta y otras obras, su postura positivista como un elemento distintivo de sus creaciones literarias, al mismo tiempo que la integra y confirma en sus reflexiones filosóficas.

Desde luego, al reconocer dicha posición de Poe, también se hace posible observar el modo con el que tanto su aplicación minuciosa de la técnica literaria como su abierta posición teórica contra la metafísica denotan todo su anhelo por ampliar el carácter de su crítica gracias al empleo intencionado de la ironía. Es en este contexto en el que cobra especial sentido, por un lado, la incorporación del narrador y, por otro lado, la puesta en escena de la figura del lector. De esta manera, el escritor entiende que la metafísica le propone un espacio narrativo donde, mediante la ironía, muestra sus inconsistencias y, finalmente, su imposibilidad por alcanzar y conducir el entendimiento humano. Por consiguiente, esto significa que, al disponer de un protagonista lector, es efectivo y lógico apelar a su figura para configurar la ironía respecto a su discernimiento sobre la metafísica. Así, por medio del despliegue de la ironía en la obra, Poe introduce su crítica en relación con dicha composición silogística y, de esta forma, la conecta con la intención de conseguir la adhesión del lector real o ficticio con su mensaje. En otras palabras, cabe destacar que así también la ironía, con la que está juzgando al saber metafísico, tiene como finalidad conseguir la deducción rápida del sujeto lector. Lo anterior permite que se perfilen diferentes planos desde los cuales operan las descripciones y comentarios del narrador respecto a los dos personajes que interaccionan en esta

\footnotetext{
${ }^{3}$ Se explica en la teoría que existen dos tipos de generales de textos: los atéticos y los téticos. De esta forma, se definen ambos: "Los textos téticos cuya estrategia fundamental es la de ocultar su carácter entimemático o sus fisuras, y los textos atéticos que en su composición dan a ver su composición silogística y ponen en crisis la posibilidad de esta composición" (Asensi, 2011a, p. 53).
} 
divertida y crítica historia. La ironía será, entonces, el recurso literario e ideológico que, en un contexto narrativo que dialoga con lo cómico y lo trágico, coloque en evidencia la presencia del modelo de mundo que se asocia con el pensar, además de lo referido con el actuar de Bon-Bon.

En consecuencia, debemos considerar que todo lo expuesto se enfatiza en la interpretación que Malaver (2013) efectúa del lenguaje literario, en especial, cuando sostiene que este actúa como nexo entre el relato y el individuo a través de los tropos o figuras del lenguaje. Pensemos, por ejemplo, como expresa la autora, que en el caso de Poe, su discurso en "Bon-Bon" apunta a la utilización de la ironía, dado que facilita la libertad cognitiva del lector para estructurar y otorgar sentido a las representaciones expuestas en el relato.

A modo de ilustración, se advierte que la historia dispone al protagonista en un pequeño y antiguo café - del cual es dueño y cocinero ${ }^{4}$ - inspirado en la antigua Grecia y ubicado en un lugar estratégico, cuestión que se determina por tener una vía de una sola entrada en Le Febre, en Rúan.

Respecto a su personalidad y vida cotidiana, se describe a Pierre Bon-Bon como un vecino muy peculiar en el pueblo, debido a que, ante todo, se trata de un versátil especialista culinario. Aunque también es retratado como un erudito seguidor de la metafísica. Es aquí donde, precisamente, se junta su aficción culinaria con su amplios conocimientos filósoficos:

Hubiera sido imposible decir cuál de las dos ramas de su trabajo le inspiraba mayor orgullo. Opinaba que las facultades intelectuales estaban íntimamente vinculadas con la capacidad estomacal. Incluso no creo que estuviera muy en desacuerdo con los chinos, para quienes el alma reside en el estómago. Pensaba que, como quiera que fuese, los griegos tenían razón al emplear la misma palabra para la mente que diafragma ${ }^{97}$. No pretendo insinuar con esto una acusación de glotonería, o cualquier otra imputación grave o perjuicio del metafísico (pp. 1-2).

Es así como, a primera vista y desde el sarcasmo, el narrador hace manifiesta su burla. Se deduce, entonces, que la idea de Poe es resaltar, a la vez, las dos aficiones del protagonista, esto es, cocinero y filósofo. Desde una perspectiva más profunda, la cita anterior tiene por objeto denunciar con sutileza y de un modo subrepticio la escasa aportación teórica y práctica que alberga la metafísica. Observándose, por otro lado, en la escena descrita, la erudición del escritor respecto a las temáticas filosóficas.

Continuando con este pasaje, se puede advertir la manera con la que el narrador explica que Bon-Bon es, en gran medida, un sujeto poco común. Esto, porque tiene algunas adicciones que reconfiguran, en el transcurso del relato y en las palabras de la voz narrativa, el suspenso y la burla que se hace de él. Destaca, en primer lugar, aquella que asevera que: “Jamás perdía la oportunidad de hacer un trato. No digo que fuera avaricioso... nada de eso. Para la satisfacción del filósofo, no era

\footnotetext{
${ }^{4}$ En el relato se ocupa el término restaurateur -el que alude al dueño y cocinero de una posada- fue utilizado en la Francia del siglo XVIII (Whole, 2005).

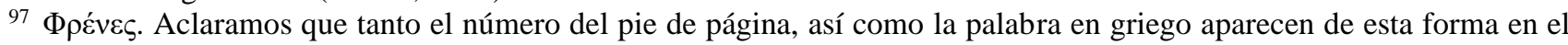
texto.
} 


\section{Tropelías. Revista de Teoría de la Literatura y Literatura Comparada, 33 (2020)}

necesario que el trato fuese ventajoso para él” (p. 2). Mayores detalles entregará el narrador por medio de las habladurías que, en su pueblo, se efectúan respecto a sus oscuros y peligrosos tratos que, en algún modo, sirven para acercarnos a un lado más enigmático de Bon-Bon. Por ello, igualmente, se afirmará que es un sujeto con facultades difíciles de explicar. Y, en tal sentido, será el narrador quien apoye la siguiente reflexión, la cual, por cierto, se encarga de avalar lo que más adelante se muestra en relato y que se origina en su diálogo con su inoportuno visitante: "Con tal que se hiciera el convenio - de cualquier género, término o circunstancia-, veíase por muchos días una triunfante sonrisa en su rostro y un guiñar de ojos llenos de malicia que daba pruebas de su sagacidad" (p. 2).

De esta forma, el relato comienza a desvelar algunas de las experiencias límite que, más tarde y a través de la ironía, convergen no solamente con aspectos ilustrativos de la metafísica, sino también con experiencias narrativas que crean situaciones de espanto y tragedia. En segundo lugar, la voz narrativa señala que Bon-Bon es un sujeto propenso a la bebida. Por eso dice que:

Por ejemplo, es sabido que pocos hombres de extraordinaria profundidad de espíritu dejan de sentirse inclinados a la bebida. Si esta inclinación es causa o más bien prueba de esa profundidad, es cosa más fácil de decir que demostrar [...] Empero, al ceder a una propensión tan clásica, no debe suponerse que el restaurateur perdía de vista esa intuitiva discriminación que caracterizaba al mismo tiempo sus ensayos y sus tortillas. Cuando se encerraba a beber, el vino de Borgoña tenía su honra, y había momentos destinados al Côte du Rhone. Para él, el Sauternes era al Medoc lo que Catulo a Homero. Podía jugar con su silogismo al probar el St. Peray, desenredar una discusión frente al Clos de Vougeot y trastornar una teoría en un torrente de Chambertin (p. 2).

Este asunto aparece relacionado con su afición culinaria y filosófica. De hecho, el escritor concibe a sus dos pasatiempos como una contradicción, pues estos se aproximan para dar salida a la ironía. Por ejemplo, tal suposición se puede confirmar a través de los pasajes breves, en donde se advierte que, al interior de su café, están dispuestos sus insumos de cocina junto a sus libros:

[...] Un plato lleno de polémicas descansaba pacíficamente sobre el aparador. Más allá había una hornada de las últimas éticas, y en otra parte una tetera de mélanges en duodécimo. Los libros de moral alemana aparecían como carne y uña en las parrillas, y un tenedor para tostadas descansaba al lado de Eusebius, mientras Platón reclinábase a su gusto en la sartén, y manuscritos contemporáneos se arrinconaban junto al asador (p. 3).

Esta cita, además, permite visualizar el creativo y dinámico juego de palabras pensado para describir el paralelismo y ordenamiento que, en este caso, existe entre la comida, los utensilios de cocina y los libros de metafísica. Con ello, el escritor está operando sobre el sentido de la metafísica, lo que podemos verificar en el transcurso del relato.

De igual modo, Poe lleva a cabo un interesante recorrido que ofrece una aguda reflexión crítica contra el discurso metafísico como son: la especulación y su falta de un método de estudio. Concretamente, esto se refleja, como hemos dicho, en la profunda erudición filosófica que tiene el escritor y que aparece con especial énfasis en la historia. De hecho, podemos encontrar que desde allí, el escritor, guía la instalación de aquellos componentes metafísicos, los cuales selecciona desde 
la historia filosófica de la Grecia Clásica y Helenística, así como de la Europa medieval y moderna. A modo ilustrativo y en lo esencial, todo lo antes mencionado se observa en el siguiente pasaje:

[...] Kant mismo -pero no llevemos las cosas más allá- debe principalmente su metafísica a BonBon. Este no era platónico ni, hablando en rigor, aristotélico; tampoco, a semejanza de Leibniz, malgastaba preciosas horas que podían emplearse mejor inventando un fricassée o, facili gradu, analizando una sensación, en frívolas tentativas de reconciliar todo lo que hay de inconciliable en las discusiones éticas. ¡Oh no! Bon-Bon era jónico. Bon-Bon era igualmente itálico. Razonaba a priori. Razonaba a posteriori. Sus ideas eran innatas... o de otra manera. Creía en Jorge de Trebizonda. Creía en Bessarion. Bon-Bon era, enfáticamente... Bon-Bonista (p.1).

Esta descripción resulta muy relevante, porque es lógico que ante la metafísica el escritor intervenga y configure, desde la interpelante voz narrativa, una categórica e ingeniosa respuesta en su contra. A partir de esto, Poe introduce su abierta predilección y cercanía con el Positivismo científico y filosófico. De esta forma, podemos advertir con claridad cómo en las premisas del pasaje anterior se deja constancia, por un lado, acerca de su amplio rigor científico y, por otro, de su reflexiva e intensa aplicación literaria de la ironía. Así pues, resulta, de igual modo, importante precisar que, a partir de su propio modelo de mundo psíquico, él traslada como escritor sus juicios críticos al contexto narrativo de "Bon-Bon". Esto quiere decir, en términos simples, que, tanto en la realidad como en la ficción, Poe se enfrenta al discurso metafísico. Incluso, nos atrevemos a decir que se trata de un lector desobediente, dado que logra cuestionar con audacia sus propuestas y sus alcances a través de esta obra.

Destaca, por cierto, en la cita, la vehemente necesidad del escritor por respaldar su ataque teórico hacia la metafísica. Por esta razón, se observa que, en función de aspectos relacionados con el método científico, la respuesta de Poe, retoma y advierte la falta de consensos teóricos que acompaña a la metafísica. Y, por otro lado, hace hincapié en su manejo del método especulativo ${ }^{5}$ que, desde su mirada, la excluye del método científico.

Queda claro, entonces, el deseo del escritor por reconstruir el discurso metafísico desde la ironía. De aquí se desprende, en líneas generales, todo el interés de Poe por la aplicación de las técnicas literarias y de las estrategias retóricas, a fin de acceder a la visualización del silogismo del relato, es decir, la ironía. De este modo, siguiendo el parecer y la ideología del narrador, se hace posible llegar a verificar cómo el pensamiento y la conducta de Bon-Bon resultan adecuadas para conseguir la representación de su entendimiento metafísico.

De esta forma, retornando al pasaje anterior, debemos destacar que la voz narrativa intenta dejar en evidencia el modo mediante el cual se habla de la indefinición metafísica de Bon-Bon. En otras palabras, esto no quiere decir que él se encuentre en desacuerdo con alguno de sus representantes y sus propuestas, sino que se confunde con la dispersión y vaguedad de sus discursos. A modo de ejemplo, las ideas de Leibniz, en la cita, son enunciadas para reforzar dicha idea a través de la crítica a su especulación y a su conformismo ontológico. En tal sentido, el escritor está dando

\footnotetext{
${ }^{5} \mathrm{Al}$ respecto, Cerezo Galán dice que "la metafísica es un saber de lo Incondicionado y, por eso, necesariamente, un saber sin condiciones" (1966, p. 75).
} 
cuenta de que el mensaje leibniziano colisiona con la comprensión metafísica de Bon-Bon. Aquí, además Poe profundiza en el escaso o nulo aporte de la metafísica, como atisbo de su incapacidad para responder a las inquietudes y a las realidades cotidianas del ser y del acontecer en el mundo.

Otro importante aspecto que se construye en la historia tiene que ver con la representación del sujeto lector. Por tanto, el asunto del mensaje irónico precisa de una apropiación textual, cuyo silogismo basado en la ironía hace posible la presencia de diversos modelos de mundo. Como se observa en el pasaje anterior, el modelo de mundo psíquico del protagonista se refuerza, en muchas ocasiones, en la vida cotidiana, siguiendo una relación directa con la metafísica y su lectura. Por esto, resulta oportuno hacer notar que el escritor concibe la historia con un enfoque irónico compuesto por una doble mirada, que se traduce y agrupa en torno a dos aspectos, a saber: el silogismo del relato y la figura del lector ficcional.

Este argumento es el que justifica la conclusión del narrador con respecto a la comprensión lectora de Bon-Bon. Conforme a esto, se afirma que este lector metafísico razona a partir de las ideas de la no contradicción (a priori) o desde la experiencia (a posteriori). Este aspecto es clave para deducir que, en concreto, Bon-Bon entiende las premisas metafísicas como verdaderas. En ello se percibe claramente que, al obtener conclusiones verdaderas, su entendimiento, así como su cuestionamiento del tema, se ve limitado a lo que indica el discurso, en este caso, metafísico. Pero hay que revisar otro asunto aquí: el modelo de mundo psíquico del protagonista. En concreto, tal modelo, como hemos establecido previamente, se ha ido configurando gracias a sus permanentes lecturas. Queda, entonces, claro que su modelo de mundo guarda estrecha relación con su aceptación del discurso metafísico. Es por esta razón que el narrador, poco a poco, va conformando y trasmitiendo al lector su enfoque crítico respecto a la disposición metafísica que asume Bon-Bon. Ahora bien, si retornamos, a modo ilustrativo, a lo expresado en la última parte del párrafo: "BonBon era, enfáticamente... Bon-Bonista" (p. 1), se nos advierte que, curiosamente, él creía en todos los metafísicos y en ninguno a la vez.

En suma, ante esta situación la voz narrativa es la encargada de clasificarlo como un sujeto que opta por seguir con su propio camino metafísico. Así, por ejemplo, bajo esta lógica y tras lo expuesto, se hace posible que el narrador exhiba lo innato de las ideas filosóficas de Bon-Bon. Por esto, su visión del asunto tiene una relación directa con el modelo de mundo psíquico del protagonista. Es decir, y según esta mirada, lo que se traza a lo largo del relato se refiere a dos aspectos que subyacen y que, asimismo, dan cabida a este tipo de modelo de mundo. De ahí que, a la vez, a través de la adhesión de Bon-Bon con la metafísica, aparece la construcción de todo un sistema de representaciones que, en líneas generales, es la que confiere sentido a sus pensamientos y conductas. Precisamente, siguiendo este modelo generado en su mente, el narrador se ve impulsado a puntualizar el asunto tanto por la burla respecto a su alto interés teórico en la metafísica como respecto a sus amplios delirios de grandeza. La última perspectiva está en correlación con este mismo modelo de mundo que hace referencia al autoconcepto de sus altas capacidades, donde, en consecuencia, se plasma la idea de que se trata de un seguidor de sí mismo. 
Un ejemplo que está en directa relación con el punto anterior, se observa en la utilización del tiempo de Bon-Bon. El relato sostiene en la voz del narrador que el protagonista dilapida su tiempo, especialmente cuando está inmerso en sus arduas lecturas metafísicas. De ahí se desprende, en sentido más amplio, la interpretación y énfasis que le otorga el narrador al escaso o nulo aporte que hace la metafísica al desarrollo del saber humano. Destaca, además, en Poe, su cuestionamiento sobre la manera con la que la metafísica hace efectiva la entrega de su mensaje. En tal sentido, se le retrata como un lector obediente y desorientado con el discurso confuso de la metafísica, a pesar, de explicitar que cuenta con un amplio interés por escudriñar en textos y efectuar lecturas minuciosas de las obras metafísicas. A modo ilustrativo, el asunto se expresa en el siguiente pasaje:

[...] Bon-Bon había explorado bibliotecas que para otros hombres eran inexploradas; había leído más de lo que otros podían llegar a concebir como lectura, había comprendido más de lo que otros hubieran imaginado posible comprender (p. 1).

Resulta, entonces, evidente la exageración con la que se exponen en la cita sus intereses y capacidades. Por cierto, esto se plasma gracias al papel que cumple su comprensión lectora, en especial, cuando por medio de ella se da cuenta de su insólita capacidad cognitiva. A la luz de lo anterior, son diversas las perspectivas desde las cuales se puede pesquisar el carácter cómico en el que se desenvuelve, por un lado, su capacidad lectora y, por otra parte, todo su interés por la metafísica. Así, junto a la capacidad cognitiva que le distingue, al igual que su interés por la lectura, aparece y se hace eco y, a la vez, espacio el modelo de mundo textual que conlleva la historia y el protagonista del relato, debido a que ambas están conectadas en algún punto con la realidad.

En esta lógica observamos que, de hecho, se manifiestan algunos de los niveles de comprensión de un texto, lo cual nos lleva a advertir que Pierre Bon-Bon, aparece en la historia como un lector obediente y desobediente a la vez. Podemos, por lo tanto, decir que su experiencia lectora se asienta en algunos de los niveles de comprensión que, de algún modo, son los que le sitúan como un sujeto capacitado para aplicar, sin mayores interferencias, por ejemplo, la competencia lingüística. A lo que se agrega su notorio interés por la lectura. Ante todo esto, lo que resulta bastante irónico es que, a pesar de contar con altas competencias lectoras y, por cierto, con una inusitada motivación por la lectura, Bon-Bon, en cambio, aparezca retratado como alguien lo suficientemente confundido con el discurso metafísico.

Tengáse en cuenta, en tal sentido, que como se ha dicho con anterioridad la descripción del dominio lector de Bon-Bon nos revela que se trata de un lector muy minucioso. De cualquier manera, esta perspectiva denota la dificultad del protagonista de ponerse en sintonía con los diversos postulados que, en todo sentido y desde la metafísica, perturban sus amplios intereses letrados. Se hace así patente el hecho de que, esté confundido o no, podemos definirle como un lector sagaz y reflexivo. Se trata, en este sentido, de un lector desobediente. Veamos, pues, con mayor detalle este asunto. Ahora bien, si observamos su interés por el saber metafísico a la luz de su desempeño lector, se descubre que es factible llegar a la siguiente conclusión: si, en efecto, ocurre que Bon-Bon no se adhiere a ninguna de las corrientes metafísicas y, además, se confunde con sus postulados, entonces 


\section{Tropelías. Revista de Teoría de la Literatura y Literatura Comparada, 33 (2020)}

surge en su mente la idea de concretar su propia teoría. Siguiendo esta deducción, podemos afirmar que el narrador amparándose en su asidua ironía, relata que el metafísico está enfrascado en la escritura de su propio libro de ética. Precisamente, tal asunto será más tarde retomado en la última parte del relato, sobre todo, cuando su inoportuno y perjudicial visitante, el diablo, se dedique a criticar por completo su obra. Por cierto, le dirá que, en efecto, sus escritos son los que le conducen a recordar las ideas de Aristóteles. El diablo reflexiona de esta forma acerca del libro que está escribiendo Bon-Bon:

Un libro muy sagaz el suyo, Pierre -continúo su Majestad, dándole una palmada de connivencia en la espalda, una vez que nuestro amigo hubo vaciado su vaso en cumplimiento del pedido de su visitante-Un libro muy sagaz, palabra de honor. Un libro como a los que a mí me gustan... Pienso, sin embargo, que su presentación del tema podría mejorarse, y muchas de sus nociones me recuerdan a Aristóteles. Este filósofo fue uno de mis conocidos más íntimos. Lo quería muchísimo por su terrible malhumor, así como por la increíble facilidad que tenía para equivocarse. En todo lo que escribió sólo hay una verdad sólida, y se la sugerí yo a fuerza de tenerle lástima al verlo tan absurdo. Supongo, Pierre Bon-Bon, que sabe usted muy bien a qué divina verdad moral aludo (p. 7).

Como se ha podido precisar, frente a la descripción que coloca de nuevo al descubierto el modelo de mundo psíquico de Bon-Bon, emerge su visión de la realidad, la cual se origina, con claridad, en su intento por escribir y divulgar su antilocuente obra de carácter ético. En efecto, se aprecia que la falta de respuestas y la imperiosa necesidad de comprender este saber, en cierto sentido, es lo que impulsa al protagonista a buscar su propio planteamiento desde la ética. De este modo, la metafísica es la que le impide alcanzar una trasgresión a sus postulados, debido a sus difusas y extensas propuestas.

En consonancia con esto, Poe atestigua que la metafísica obedece al tipo de discurso que confunde y reduce el entendimiento del individuo. Como advierte, en este mismo sentido, Bunge (2013) cuando afirma que una doctrina filosófica, ante todo, nos sitúa y enfrenta con un tipo de conocimiento ambivalente. Esto porque, en términos simples, puede iluminar o, por el contrario, incidir de forma directa en la parcelación y encierro del entendimiento humano. Por lo tanto, la Teoría de Asensi, defiende una mirada que reconoce la importancia de conseguir una lectura que, en definitiva, movilice el pensamiento crítico del sujeto.

Al observar el asunto, es oportuno tener en cuenta las posibilidades de trasgresión del discurso que, por cierto, está dispuestas en un texto atético. Por consiguiente, sus repercusiones operan siguiendo los juicios y expresiones que se hacen respecto a la metafísica, tanto en los comentarios como en las descripciones del narrador. Esto, de hecho, se aprecia totalmente en este relato literario cuyo trasfondo crítico y burlesco potencia la construcción de estrategias discursivas ligadas a la irrupción y escenificación de la lectura. En consecuencia, la teoría cobra todo su valor cuando enfatiza su mirada crítica y, de este modo, desvela las relaciones entre el lector y el discurso. Todo esto porque es, justamente, el lector quien se enfoca en mostrar su posición frente a lo que escucha, lee u observa en los medios literarios y culturales (Asensi, 2007). 
Otro aspecto que, igualmente, tiene relación con la articulación discursiva del silogismo es el que, en este caso, se expresa a partir de la ironía. Es por ello que la voz narrativa, a lo largo del relato, se organiza mediante dos tipos de ironía. La primera es la cómica y, la segunda, es la trágica. De hecho, en el caso particular de la ironía cómica, se observa que su puesta en escena se ocupa durante todo el entramado narrativo de la historia. Respecto de la ironía cómica, el narrador simplemente se aboca a relatar las peculiaridades físicas y las capacidades intelectuales del protagonista:

[...] Por eso, aunque Bon-Bon tenía apenas tres pies de estatura y su cabeza era minúscula, nadie podía contemplar la rotundidad de su vientre sin experimentar una sensación de magnificencia que llegaba a lo sublime. En su tamaño, tanto hombre como perros veían un arquetipo de sus capacidades y, en su inmensidad, el recinto adecuado para su alma inmortal (p. 3).

En el caso de la ironía trágica, su representación se despliega con especial énfasis en la última parte del relato, donde se lleva a cabo una conversación itinerante y nada convencional entre BonBon y su visitante, el diablo. Esta dinámica se inicia cuando el narrador describe sus diálogos, luego del arribo del diablo al café de Bon-Bon. Instalándose así un juego irónico con el discurso metafísico, el que, en definitiva, se enlaza con hechos escalofríantes. A modo ilustrativo, aquí se resume lo dicho previamente:

- ¿Y qué piensa usted... qué piensa usted... ¡hic!... de Epicuro?

- ¿Qué pienso de quién? -preguntó el diablo estupefacto-. No pretenderá usted encontrar ningún error en Epicuro, espero. ¿Qué pienso de Epicuro? ¿Habla usted de mí, caballero? ¡Epicuro soy yo! Soy el mismo filósofo que escribió cada uno de los trescientos tratados que tanto celebraba Diógenes Laercio (pp. 7-8).

Las apariciones de la ironía cómica y la ironía trágica en este relato tienen como finalidad establecer una aproximación textual con el lector de la obra, cuestión que básicamente responde al permanente interés de Poe por conseguir que este reconozca y se adhiera con relativa facilidad a su mensaje de fondo. Téngase en cuenta, en tal sentido, que la ironía inserta en el texto literario opera, entonces, sobre la deducción del mensaje. Por esto, es que ella aparece implícita y explícita en la obra. Desde el punto de vista literario, la tarea que asume el escritor que instala la ironía se convierte en un eje de suma importancia para clarificar cómo se activa su propuesta comunicativa. Para ello, en este caso, Poe recurre a poner en evidencia con toda claridad el modelo de mundo psíquico del protagonista, donde actúa como lector ficcional y, a partir del cual, pretende acercarse al lector real por medio de su abierta y creativa crítica a la metafísica. La ironía, además, se abre a la utilización de distintos registros, citas y comentarios que, en términos literarios, ponen en escena la parodia y el discurso directo e indirecto, cuyo objeto es posibilitar el entendimiento general y específico del sujeto. Igualmente, también se plantea que la ironía tiene la capacidad de implicar al lector con el mensaje, observándose así que su principal desafío consiste en hallar las implicaciones lingüísticas, narrativas y del contexto. Las que, en rigor, pueden llegar a ser reconocidas por el sujeto gracias a sus deducciones y, más específicamente, por medio de la intencionalidad comunicativa del autor 
(Barreras Gómez, 2001-2002). Al decir esto, en realidad, lo que nos interesa en el caso de "BonBon", a partir de lo antes indicado, es la manera en que el autor del relato logra que el lector real de su obra consiga alcanzar un rápido y efectivo entendimiento de su silogismo. Así, en esta obra se aprecia cómo ambas ironías muestran la representación que Poe hace del protagonista y de su modelo de mundo, que encierra su significativa y amplia relación con la lectura metafísica.

Podríamos decir, en suma, que la estructura textual de la obra propone un nexo intenso entre la subjetividad del lector y la representación de la realidad que le corresponden. Como indica Asensi (2018), tanto la reducción alegórica como la acción modelizadora de los discursos dan cuenta del modelo de mundo psíquico del sujeto y del modelo de mundo discursivo del texto. Ante esto, se deduce que el entorno contextual de Bon-Bon es, de hecho, altamente propicio para efectuar sus lecturas metafísicas. De igual modo, resulta pertinente afirmar que, por ejemplo, si consideramos la época histórica en que se halla el protagonista, son pocas las opciones que él tiene para dirigir sus pensamientos y construir sus modelos de mundo. Así pues, el modelo discursivo de Poe aquí involucra la puesta en escena de un discurso metafísico que, si bien resulta clave para entender cómo se gesta el pensamiento social y cultural de occidente, es poco claro y deficiente en sus métodos científicos. No obstante, Bon-Bon le sigue y, por ello, su modelo de mundo psíquico está construido en torno a su posición de conformidad con la metafísica, es decir, con su modelo de mundo discursivo. Asimismo, su modelo de mundo como lector visibiliza su propia resistencia y le implica en la escritura de su obra ética, invirtiendo así el discurso confuso que le entrega la metafísica clásica y moderna.

\section{Conclusiones}

En este trabajo hemos trazado, en primer lugar, el análisis de algunos de los postulados de la crítica como sabotaje o modelos de mundo, especialmente desde la perspectiva del sujeto lector y de su relación con el discurso. En el relato corto de "Bon-Bon", el discurso crítico e irónico del narrador encarna en plenitud la denuncia contra la metafísica que, en este contexto ficcional, realiza Edgar Allan Poe. A partir de esto, la propuesta teórica y metodológica de Manuel Asensi (2007, 2011a, 2011b, 2013, 2016, 2018) revela la posibilidad, como hemos observado, de encontrar y analizar el silogismo de este texto atético.

Todo ello gracias a la función del protagonista lector de "Bon-Bon", así como del mensaje que se desprende de sus lecturas metafísicas. En suma, desde el silogismo se deconstruye el discurso metafísico y se muestra a sus posibles lectores, aplicando el recurso textual de la ironía. De hecho, el estilo narrativo y la posición teórica de Poe pone de manifiesto la importancia que el escritor otorga, como hemos visto, al arduo y permanente trabajo narrativo. Merece, también, la pena recordar que su interés por conseguir la implicación lectora del sujeto que encuadra toda su creación literaria bajo la técnica de la composición literaria. 
Por esta vía, es que ha sido posible además verificar la posición filosófica y de creación literaria que asume Poe. Demostrando así, el sentido e importancia que tiene conseguir un lector crítico que apruebe o desapruebe el discurso, encontrando su silogismo y sus modelos de mundo. Esto obedece a que el acto lector como tal significa y, al mismo tiempo, trasgrede la pasividad de quien lee. Por ello, se sitúa como una actividad cognitiva de gran interés para la literatura, la pedagogía, la psicología, la filosofía del lenguaje y, más recientemente, para la ciencia cognitiva.

Por último, cabe destacar que el método y análisis de la teoría puede ser incorporada directamente al ámbito pedagógico. En este sentido, la revisión de aspectos de la realidad y sus posibilidades discursivas, de un modo u otro, disponen al individuo hacia la toma posiciones ideológicas, éticas y valóricas (López Astorga, 2011). Por eso, resulta pertinente considerar próximos estudios que revisen sus posibles implicaciones didácticas en la literatura.

\section{Referencias bibliográficas}

ASENSI, M. (1998). Historia de la teoría de la literatura. Desde los inicios hasta el siglo XIX. Valencia, Tirant Lo Blanch.

(2007). ¿Qué es la crítica literaria como sabotaje? (especulaciones dispersas en torno a la crítica en la era de la posglobalización). Anthropos. Huellas del conocimiento, 216, 73-82.

- (2011a). La crítica y sabotaje. Barcelona: Anthropos / Siglo XXI.

(2011b). Hermenéutica, deconstrucción y sabotaje. Ámbitos, Revista de estudios de ciencias sociales y humanidades, 25, 13-19.

(2013). Modelos de mundo y lectores/as desobedientes. En B. Ferrús y M. Zabalgoitia (Coords.), Anthropos 237: La crítica como sabotaje de Manuel Asensi (pp. 17-30). Barcelona, Anthropos / Siglo XXI.

- (2016). Teoría de los modelos de mundo y teoría de los mundos posibles. Actio Nova: Revista de Teoría de la Literatura y Literatura Comparada, 38-55.

- (2018) ¿Qué dice la fantasía de nuestro mundo? Sobre el concepto de "Reducción alegórica". Actio Nova. Revista de Teoría de la Literatura y la Literatura Comparada, 2, 310-330. Doi: https://doi.org/10.15366/actionova2018.2.

BARRERAS GÓMEZ, A. (2001-2002). El estudio de la ironía en el texto literario. Cuadernos de Investigación Filológica, 27-28, 243-266.

BUNGE, M. (2013). Filosofía y fobosofías. Universum, Revista de Humanidades y Ciencias Sociales, 28(2), 17-31.

CABALlERO, A. (2013). Sabotaje, crítica y violencia política. En Ferrús, B. y Zabalgoitia, M. (Coords.), Anthropos 237: La crítica como sabotaje de Manuel Asensi (pp. 71-83). Barcelona, Anthropos / Siglo XXI.

CALAFELL SALA, N. (2012). El sabotaje de una praxis genérica: el ejemplo de Luisa Valenzuela [artículo en línea] 452oF. Revista Electrónica de Teoría de la Literatura y Literatura 
Comparada, 7, 92-152. Obtenido el 23 de septiembre de 2017 desde http://www.452f.com/pdf/numero07/07_452f-mis-nuria-calafell-sala-orgnl.pdf.

CEREZO GALÁN, P. (1966). El fundamento de la metafísica en Leibniz. Anales del Seminario de Metafísica, 75-105.

GIL GUERRERO, H. (2008). Poética narrativa de Jorge Luis Borges. Madrid, Iberoamericana. JOHNSON-LAIRD, P. N. (1983). Mental Models. Towards a Cognitive Sciende of Language, Inference and Consciousness. Cambridge, Uk., Cambridge University Press.

(2006). How we reason. Oxford, Oxford University Press.

- (2010). Against logical form. Psychologica Belgica, 50, 193-221.

(2012). Inference with Mental Models. In K. J. Holyoak, \& R. G. Morrison (Eds.), The Oxford

Handbook of Thinking and Reasoning (pp. 134-154). New York: Oxford University Press. Doi. http://dx.doi.org/10.1093/oxfordhb/9780199734689.013.0009.

KAUFMAN, G. y LIBBY, L. K. (2012). Changing Beliefs and Behavior Through Experience-

Taking. Journal of Personality and Social Psychology, 103(1), 1-19.

KIDD, D. C. y CASTANO, E. (2013). Reading literary fiction improves theory of mind. Science, 342 (6156), 377-380.

_ (2017). Different stories: How levels of familiarity with literary and genre fiction relate to mentalizing. Psychology of Aesthetics, Creativity, and the Arts, 11(4), 474-486.

LÓPEZ-ASTORGA, M. (2011). Heurísticos y racionalidad: ¿la ignorancia beneficia a los estudiantes en algún sentido? Educar em Revista, 41, 215-229.

- (2019). An Language acquisition and innate cognitive abilities: An approach from the mental models theory. Círculo de Lingüística Aplicada a la Comunicación, 77, 233-242. Disponible en http://webs.ucm.es/info/circulo/no77/Lopezastorga.pdf. Doi: http://dx.doi.org/10.5209/CLAC.63286.

MALAVER, N. (2013). Literatura, historia y memoria. Hallazgos, 10(20), 35-47.

MATAMOROS, M. (2011). Elementos del formalismo en la teoría de la composición. Lengua y Voz, 1(1), 3-9.

PIZARRO OBAID, F. (2011). Transformaciones y nuevas figuras de lo nervioso en la construcción de los relatos de Edgar Allan Poe. Acta Literaria, 43, 79-93.

POE, E. A. (2008). Cuentos completos. Prólogo, traducción y notas de Julio Cortázar. España, Augur Libros.

SOVA, D. B. (2007). Critical Companion to Edgar Allan Poe: A Literary Reference to His Life and Work. New York, Facts On File.

TURNER, R. y FELISBERTI, F. (2018). Relationships between fiction media, genre, and empathic abilities. Scientific Study of Literature, 8(2), 261-292. Doi: https://doi.org/10.1075/ssol.19003.tur.

WHOLE, R. (2005). Lo que Einstein contó a su cocinero II. Traducción de Mayra Paterson Hernández. Barcelona, Ediciones Robinbook.

ZIMMERMAN, B. (2005). Edgar Allan Poe: Rhetoric and Style. Montreal, MacGill-Queen's University Press. 